phương pháp này là bộc lộ được dây VII trong ống tai trước khi lấy u, vì vậy khả năng bảo tồn dây VII tốt hơn. Nhược điểm của đường mổ này là cần phải có sự phối hợp của bác sĩ tai mũi họng, chuyên sâu về đường mổ này, và vì vậy trong điều kiện tại trung tâm của chúng tôi (không có chuyên khoa tai mũi họng), khả năng phối hợp này không được áp dụng thường xuyên. Để khắc phục nhược điểm của đường mổ sau xoang sigma như đã nói ở trên, chúng tôi từ năm 2019 đã áp dụng kỹ thuật mài thành sau lỗ tai trong theo phương pháp Ohat cho kết quả tốt.

Chụp MRI sau mổ được tiến hành thường quy cho tất cả các bệnh nhẩn sau mổ, khi so sánh trước và sau mổ, theo phân độ KOOS, kích thước u giảm có ý nghĩa thống kễ (bảng 3). Chúng tôi lựa chọn mục tiêu của phẫu thuật là lấy tối đa thể tích $u$ và bảo tồn tối đa chức năng thần kinh VII, tương tự với quan điểm của Akinduro [3]. Phần u tồn dư có thể được theo dõi hoặc điêu trị xạ phẫu theo cập nhật hướng dẫn điểu trị của hiệp hội ung thư thần kinh châu Âu.

Một trong các yếu tố quan trọng khác đánh giá hiệu quả điều trị phẫu thuật là chức năng của dây VII. Khi so sánh mức độ liệt mặt theo thang điểm House-Brackmann, chúng tôi thấy có sự cải thiện có ý nghĩa thống kê. Chúng tôi giải thích hiện tượng này là bởi ngay sau mổ, tuy mức độ bảo tồn giải phẫu dây VII, song tình trạng liệt vẫn xuất hiện là do sự căng kéo, phù nể của dây VII trong mổ. Chức năng của dây VII cần phải có thời gian để phục hồi, vì vậy ở thời điểm khám lại tình trạng liệt dây VII có xu hướng tốt hởn. Các bệnh nhân trong nhóm nghiên cứu của chúng tôi thường có sự cải thiện rõ rệt tình trạng liệt mặt sau mổ ở thời điểm 6 tháng sau mổ.

\section{KẾT LUÂ̂N}

U dây thần kinh số VIII dạng nang là một thể đặc biệt của u dây thần kinh số VIII. Không có sự khác biệt về biểu hiện lâm sàng giữa dạng nang hay dạng đặc của u dây thần kinh số VIII. Tuy nhiên tốc độ phát triển của u dạng nang cao nhanh hơn so với dạng đặc. Điều trị phẫu thuật còn nhiều khó khăn do nguy cơ tổn thương dầy VII cao hơn. Đường mổ sau xoang sigma là phương pháp an toàn, có hiệu quả trong điều trị u dây thần kinh số VIII dạng nang.

\section{TÀI LIÊU THAM KHẢO}

1. Wandong, S., et al., Cystic acoustic neuroma. J Clin Neurosci, 2005. 12(3): p. 253-5.

2. Thapa, P.B., et al., Vestibular Schwanomma: An Experience in a Developing World. World J Oncol, 2019. 10(2): p. 118-122.

3. Akinduro, O.0., et al., Outcomes of large vestibular schwannomas following subtotal resection: early post-operative volume regression and facial nerve function. J Neurooncol, 2019.

4. Berkowitz, O., et al., Gamma Knife Radiosurgery for Vestibular Schwannomas and Quality of Life Evaluation. Stereotact Funct Neurosurg, 2017. 95(3): p. 166-173.

5. Rezaii, E., et al., Effect of Institutional Volume on Acoustic Neuroma Surgical Outcomes: State Inpatient Database 2009-2013. World Neurosurg, 2019. 129: p. e754-e760.

6. Lees, K.A., et al., Natural History of Sporadic Vestibular Schwannoma: A Volumetric Study of Tumor Growth. Otolaryngol Head Neck Surg, 2018. 159(3): p. 535-542.

7. Stangerup, S.E., et al., The natural history of vestibular schwannoma. Otol Neurotol, 2006. 27(4): p. 547-52.

8. Awan, M.S., et al., Vestibular schwannomas: clinical presentation, management and outcome. J Pak Med Assoc, 2001. 51(2): p. 63-7.

\title{
ĐÁNH GIÁ CHỈ SỐ KHÚC XẠ GIÁC MẠC VÀ CHIỀU DÀI TRỤC NHÃN CẦU TRỂN MẤT CẦN THỊ CAO
}

\section{TÓM TẮT.}

Mục tiêu: Đánh giá chỉ số khúc xạ giác mạc, chiều dài trục nhãn câu và tìm hiểu mối liển quan giữa các chỉ số khúc xạ giác mạc, chiều dài trục nhãn câu

${ }^{1}$ Bệnh viện Mắt Trung Uơng

Chịu trách nhiệm chính: Nguyễn Thị Thu Hiền

Email: thuhienvnio@gmail.com

Ngày nhận bài: 5.01.2021

Ngày phản biện khoa học: 3.3.2021

Ngày duyệt bài: 15.3.2021

\section{Nguyễn Thị Thu Hiền', Phạm Thị Minh Châu1}

trên mắt cận thị cao. Đối tượng và phương pháp nghiên cứu: nghiên cứu mố tả, nghiên cứu được thực hiện ở 88 bệnh nhân (168 mắt), tuổi từ 12 đển 47 được chẩn đoán là tật cận thị cao trên -6,00D tại khoa khúc xạ bệnh viện Trung ương. Kết quả: Độ cận trung bình là $-8,76 \pm 2.61 \mathrm{D}$. Khúc xạ giác mạc trung bình là 43,71 $\pm 1.65 \mathrm{D}$. Chiều dài trục nhãn cầu trung bình là $27,33 \pm 1,49 \mathrm{~mm}$. Khúc xa giác mạc và mức độ cận thị có tương quan tuyến tính $(r=-0,209$; $p=0,007)$. Chiều dài trục nhãn câu và mức độ cận thị cao có mối tương quan chặt chẽ với nhau $(r=-0,762$ và $p<0,001)$. Chỉ số khúc xạ giác mạc và chiêu dài 
trục nhãn cầu không có liên quan tuyến tính với nhau. Kết luân: Mức độ cận thị liên quan cả với khúc xa giác mạc và chiều dài trục nhãn câu. Hai chỉ số này có giá trị trong chẩn đoán, chỉ định và tiên lượng trong phẫu thuật khúc xa.

Tư khóa: cận thị cao, khúc xạ giác mạc, chiều dài trục nhãn cầu

\section{SUMMARY}

\section{EVALUATION OF CORNEAL REFRACTION} POWER AND AXIS LENGTH IN HIGH MYOPIA

Objective: To evaluate the corneal refraction power (CRP), axis length (AL) and finding relationships between corneal refraction power, axis length in high myopia patient. Research methods: descriptive study, the study was conducted in 88 patients (168 eyes) were diagnosed high myopia in Central Fye hospital. Results: The average myopia was $-8.76 \pm 2.61 \mathrm{D}$. The CRP average was $43.71 \pm$ 1.65D. The AL average was $27.33 \pm 1.49 \mathrm{~mm}$. CRP and myopia degree were a statistically significant association ( $r=-0.209 ; p=0.007)$. AL and myopia degree were a closely statistically significant association $(r=-0.762 ; p<0.001)$. The CRP and the AL were not a statistically significant association ( $p>0.05)$. Conclusion: myopia degree was linearly correlated with both CRP and AL. Measuring CRP and $\mathrm{AL}$ was useful in diagnosis, priscription and prognosis myopia surgery.

Key words: high myopia, corneal refraction power, axis length.

\section{I. ĐĂT VẤN ĐỀ}

Tỷ lệ cận thị trên thế giới đang gia tăng rất nhanh, theo đó tỷ lệ cận thị cao cũng gia tăng và nguy cơ biến chứng do cận thị cao đang là vấn để được quan tâm. Dự đoán đển năm 2050, tỷ lệ cận thị sẽ tăng lên đến $52 \%$ dân số thế giới (khoảng 5 tỷ người), trong đó cận thị cao chiếm 10\% (khoảng 911 triệu người). Đây sẽ là 1 gánh năng rất lớn khi tỷ lệ cân thi và cận thị cao chủ yểu nằm ở nhóm thanh thiếu niên, lứa tuổi lao động chính, đặc biệt là ở các nước Đông nam Á, trong đó có Việt Nam. ${ }^{1,2}$

Theo y văn cận thị cao có thể kèm theo khúc xa giác mạc vồng cao và/hoắc trục nhãn câu kéo dài ra. Tuy nhiên trên thực tế lâm sàng cho thấy nhiều bệnh nhân cận thị cao nhưng giác mạc rất dẹt, điều đó gây khó khẳn cho việc chỉ định phẫu thuật Laser trên bề mặt giác mạc để điều trị cận thị. Các nghiên cứu về chiều dài trục trên mắt cận thị đều kết luận cận thị cao thường làm cho trục nhãn cầu kéo dài ra, dẫn đến các tổn thương thoái hóa của võng mạc và có nguy cơ gây mù do bong võng mạc. Đối với một phẫu thuật viên khúc xạ, trên những bệnh nhân cận thị trên -6.00D các chỉ số như: độ dày giác mạc, khúc xạ giác mạc, chiều dài trục nhãn cầu càng cần được chú ý bởi nếu Laser trên bề mặt giác mạc phải đòi hỏi giác mạc phải đủ dày và đủ vồng để có thể phẩu thuật được an toàn và triệt tiêu hết độ cận. Ngoài ra với những mắt cận thị cao càng cần được chú ý do nguy cơ biến chứng trên nhóm đối tượng này. Dựa vào việc đánh giá chỉ số khúc xạ giác mạc và chiều dài trục nhãn cầu, tìm hiểu mối liên quan giữa các chỉ số này và mức độ cận thị giúp cho các phẫu thuật viên khúc xạ có thể cân nhắc và tư vấn cho bệnh nhân lựa chọn được phương pháp điều trị thích hợp, đồng thời tiên lượng được kết quả của phẫu thuật. Vì vậy chúng tổi tiến hành nghiên cứu đề tài này nhằm mục tiêu: Đánh giá các chỉ số: khúc xạ giác mạc và trục nhãn cầu trên mắt cận thị cao; tìm hiểu mối liên quan giữa các chỉ số: khúc xạ giác mạc, trục nhãn cầu và mức độ cận thị cao.

\section{II. ĐỐI TƯợNG VÀ PHƯƠNG PHÁP NGHIÊN CỨU}

2.1 Đối tượng nghiên cứu: Nghiên cứu được thực hiện tại khoa Khúc xạ - Bệnh viện mắt Trung ương trên đối tượng nghiên cứu với các tiêu chuẩn sau:

Tiêu chuẩn lựa chọn: Bệnh nhân được chẩn đoán cận thị từ $-6,00 \mathrm{D}$ trở lển sau soi bóng đồng tử có tra thuốc liệt điều tiết, ở môt hoặc hai mắt, có hoặc không kèm loạn thị, tuổi từ 12 tuổi trở lên. Gia đình và người bệnh đồng ý tham gia nghiên cứu.

Tiêu chuân loại trừ: bệnh nhân có các tổn thương thực thể tại mắt: sẹo giác mạc, bong võng mạc, lác, sụp mi....

\subsection{Phương pháp nghiên cứu}

Thiết kế nghiên cứu: nghiên cứu mô tả

Cõ̃ mẫu: nghiên cứu được thực hiện trên 168 mắt của 88 bệnh nhân.

Phương tiện nghiên cứu: máy chiếu thị lực, hộp thử kính, máy đo khúc xạ tự động, máy soi bóng đồng tử, máy sinh hiển vi khám bệnh, máy soi đáy mắt, máy chụp bản đồ giác mạc Schwind Sirius, máy siêu âm B, máy Zeiss IOL Master, thuốc Cyclogyl 1\%, bệnh án nghiên cứu.

Các bước tiến hành nghiên cứu:

- Hỏi một số thông tin: tuổi, giới tính, thời gian phát hiện cận.

- Đo khúc xạ soi bóng đồng tử sau tra thuốc Cyclogyl $1 \%$

- Đo khúc xạ chủ quan cầu tối ưu và trụ Jackson

- Khám mắt và soi đáy mắt

- Đánh giá tình trạng dịch kính võng mạc

- Đo khúc xạ giác mạc, đo chiều dài trục nhãn câu.

Xử lí số liệu: số liệu được thu thập và xử lí bằng phần mềm SPSS 20.0 


\section{KẾT QUẢ NGHIÊN CỨU VÀ BÀN LUÂN \\ 3.1 Đăc điểm bệnh nhân}

Đăcc điểm chung: Nghiên cứu của chúng tôi thực hiện trên 88 bệnh nhân gồm 168 mắt cận thị cao. Tuổi của bênh nhân trong khoảng từ 12 tới 47 tuổi. Độ tuổi trung bình là 20,35 \pm 7,19

Tổng số mắt nghiên cứu là 168 mắt, trong đó số mắt của bệnh nhân nam là 61 mắt tương ứng với $36,3 \%$, còn số mắt của bệnh nhân nữ là 107 mắt tương ứng với $63,7 \%$.

Tình hình cận thị: Mức độ cận thị được chia thành 2 nhóm: Nhóm 1 từ $\leq-6,00 \mathrm{D}$ đển $\geq-$ $7,75 \mathrm{D}$ và nhóm 2 từ $\leq-8,00 \mathrm{D}$. Công suất cận thị trung bình là $-8,75 \pm 2,61 \mathrm{D}$, trong đó công suất cận thấp nhất là $-6,00 \mathrm{D} ;$ cao nhất là $-19,75 \mathrm{D}$. Số mắt nhóm 1 là 68 mắt chiếm tỷ lệ $40,5 \%$; số mắt nhóm 2 là 100 mắt chiếm tỷ lể $59,5 \%$; sự khác biêt này có ý nghĩa thông kê với $p<0,05$.

Thời gian phát hiện cận thị. Thời gian phát hiện cận thị trung bình là $11,21 \pm 6,01$ năm, trong đó thời gian phát hiện cận ngắn nhất là 1 năm, thời gian phát hiện cận dài nhất là 34 năm.

\subsection{Kết quả một số chỉ số sinh học}

Khúc xạ giác mạc. Khúc xạ giác mạc (được tính bằng trung bình cộng của khúc xạ giác mạc đo bằng máy chụp bản đồ giác mạc ở kinh tuyển dẹt nhất và kinh tuyến vồng nhất) nhận giá trị từ 41,45D đến 52,50D. Giá trị trung bình của khúc xa giác mac là $43.71 \pm 1.65 \mathrm{D}$.

Kết quả nghiên cứu của chúng tôi cũng tương tự như kết quả nghiên cứu của một số tác giả khác trên thế giới. Trong nghiển cứu của Baradaran năm $2017^{3}$ cho kết quả khúc xa giác mạc khi đo bằng máy chụp bản đồ Galilei là $42.98 \pm 1.69 \mathrm{D}$, và khi đo bằng Javal là $43.96 \pm$ $1.54 \mathrm{D}$ hay trong nghiên cứu của Kadhim và

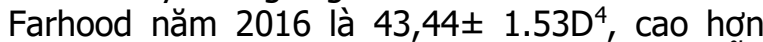
nhóm cận thị nặng $(42,93 \pm 1.15 \mathrm{D})$ của Nguyễn Thị Thanh Dung ${ }^{6}$ năm 2017. Nhìn chung chỉ số khúc xạ giác mạc trên mắt cận thị rất khác nhau trong các nghiên cứu.

Giá trị trung bình khúc xạ giác mạc theo mức độ cận thị

Bảng 1: Giá trị trung bình khúc xa giác mạc theo mức độ cận thị

Mức độ cận thị Khúc xạ giác mạc ( $\bar{X}$, SD)

Nhóm 1 $43.50 \pm 1.32$

Nhóm $2 \quad 43.85 \pm 1.83$

Khúc xạ giác mạc trung bình giữa nhóm 1 và nhóm 2 không có sự khác biệt có ý nghĩa thống kê với $p>0,05$.

Chiêu dài trục nhãn câu. Chiều dài trục nhãn cầu trung bình là $27,33 \pm 1,49 \mathrm{~mm}$. Mắt có trục ngắn nhất là $24,23 \mathrm{~mm}$ và trục dài nhất là
$32.83 \mathrm{~mm}$.

Giá trị trung bình của chiêu dài trục nhãn câu theo mức độ cận thị

Bảng 2: Giá trị trung bình chiều dài trục nhãn cầu theo mức độ cận thị

\begin{tabular}{|c|c|}
\hline $\begin{array}{c}\text { Mức độ cận } \\
\text { thị }\end{array}$ & $\begin{array}{c}\text { Chiều dài trục nhãn câu } \\
(X, \text { SD) }\end{array}$ \\
\hline Nhóm 1 & $26,49 \pm 0,93 \mathrm{~mm}$ \\
\hline Nhóm 2 & $27,90 \pm 1,56 \mathrm{~mm}$ \\
\hline
\end{tabular}

Chiều dài trục nhãn cầu trung bình của nhóm 1 là $26,49 \pm 0,93 \mathrm{~mm}$, ngắn hơn chiều dài trục nhãn câuu trung bình của nhóm 2 là 27,90 \pm $1,56 \mathrm{~mm}$, sự khác biệt có ý nghĩa thống kê với $\mathrm{p}<0,001$.

Chiều dài trục nhãn cầu trung bình trong nghiên cứu của chúng tôi lớn hơn so với chiều dài trục nhãn cầu trung bình của mắt chính thi trong nghiên cứu của Hoàng Hồ năm 1996 trên 261 mắt người trưởng thành (nữ giới là 22,77 \pm $0,06 \mathrm{~mm}$ và ở nam giới là $23,5 \pm 0,10 \mathrm{~mm}$ ) và lớn hơn chiều dài trục nhãn cầu của nhóm cân thị trung bình trong nghiên cứu của Nguyễn Thị Thanh Dung năm $2017(25,63 \pm 0.78 \mathrm{~mm})^{6}$. Điều này cho thấy mắt cận thị càng cao thì chiêu dài truc nhãn câu càng dài.

3.3 Liên quan giữa các chỉ số sinh học và mức độ cận thị. Tương quan giữa khúc xạ giác mạc và mức độ cận thị.

Hai chỉ số khúc xạ giác mạc và độ cận thị có tương quan tuyến tính nghịch biến yếu với $r=-$ 0,209 có ý nghĩa thống kê với $p=0,007$ có nghĩa cân thi càng năng thì khúc xa giác mac càng cao. Phương trình tương quan được biểu diễn dưới dạng: $y=-0.131 * x+42,559$ (trong đó $y=$ khúc xạ giác mạc trung bình, $x=$ mức độ cận thị).

Xét mối tương quan giữa khúc xạ giác mạc và mức độ cận thị trong từng nhóm cận thị cao

Bảng 3: Tương quan giữa khúc xa giác mạc và mức độ cận thị theo từng nhóm cận thi cao

\begin{tabular}{|c|c|c|}
\hline $\begin{array}{c}\text { Mối tương quan } \\
\text { giữa các chỉ số }\end{array}$ & Nhóm 1 & Nhóm 2 \\
\hline $\begin{array}{c}\text { Khúc xă GM và mức } \\
\text { độ cận thị }\end{array}$ & $\begin{array}{r}\mathrm{r}=-0.20 \\
\mathrm{p}=0,045\end{array}$ & $\mathrm{r}=-0,163$ \\
$\mathrm{p}=0.184$
\end{tabular}

Theo từng nhóm cận thị cao chúng tôi thấy: Nhóm 1 có mối tương quan nghịch biến giữa khúc xạ giác mạc và mức độ cận thị. Ngược lại, nhóm 2 có mức độ cận thị cao hơn lại không thấy có mối tương quan giữa khúc xạ giác mạc và mức độ cận thị.

Tương tự với kết quả nghiên cứu của chúng tôi, nghiên cứu của Olsen và cộng sự lại cho rằng khúc xạ giác mạc càng lớn thì mức độ cận thị lại càng nặng ${ }^{5}$ 
Trái với kết quả nghiên cứu của chúng tôi, nghiên cứu của Nguyển Thị Thanh Dung năm $2017^{6}$ hay trong nghiên cứu của Chen và cộng sự năm 2009 lại cho kết quả không có mối tướng quan giữa khúc xạ giác mạc với mức độ cận thị

Tương quan giữa chiêu dài trục nhãn cầu và mức độ cận thị cao.

Hai chỉ số chiều dài trục nhãn cầu và mức độ cận thị cao có mối tương quan nghịch biến chặt chẽ với hệ số tương quan $r=-0,762$ và $p<0,001$. Trục nhãn cầu càng dài thì độ cận càng cao, mối tương quan giữa 2 chỉ số này rất chặt chẽ với phương trình tương quan: $y=-0,433 * x+23,538$ ( $x$ là chiều dài trục nhãn cầu, y là giá trị tuyệt đối cầu tương đương)

Bảng 4. Tương quan giữa chiều dài trục nhãn cầu và mức độ cận thị cao theo nhóm cận

\begin{tabular}{|c|c|c|}
\hline $\begin{array}{c}\text { Mối tương quan } \\
\text { giữa các chỉ số }\end{array}$ & Nhóm 1 & Nhóm 2 \\
\hline $\begin{array}{c}\text { Trục nhãn câu và } \\
\text { mức độ cận thị }\end{array}$ & $\begin{array}{c}r=-0,324 \\
\mathrm{p}=0,007\end{array}$ & $\begin{array}{c}\mathrm{r}=-0,745 \\
\mathrm{p}=0,000\end{array}$ \\
\hline
\end{tabular}

Khi tìm hiểu mối liên quan giữa chiêu dài trục nhãn cầu và mức độ cận thị cao ở từng nhóm nghiên cứu chúng tôi thấy rằng:

ở nhóm 1 giữa chiều dài trục nhãn cầu và mức độ cận thị cao có mối tương quan tuyến tính nghịch biến với $r=-0,324$ và $p<0,05$.

ở nhóm 2 giữa chiêu dài trục nhãn cầu và mức độ cận thị cao có mối tướng quan tuyến tính nghịch biến với $r=-0,745$ và $p<0,001$.

Kết quả nghiên cứu của chúng tôi cũng phù hợp với những nghiên cứu trước đây của các tác giả khác như Đường Thị Anh Tho (2008) ${ }^{6}$, Chen $(2009)^{7}$. Tất cả các nghiên cứu trên đều cho thây mức độ cận càng cao trục nhãn cầu càng dài.

Tương quan giữa khúc xạ giác mạc và chiều dài trục nhãn cầu. Giữa khúc xạ giác mạc và chiều dài trục nhãn cầu không có mối tương quan tuyến tính với hệ số tương quan p>0.05.

Xét mối tương quan giữa khúc xạ giác mạc và chiều dài trục cận thị trong từng nhóm cận thị

Bảng 5. Tướng quan giữa chiều dài trưc nhãn câuu và khúc xạ giác mạc theo nhóm cận thị

\begin{tabular}{|c|c|c|}
\hline $\begin{array}{c}\text { Mối tướng quan } \\
\text { giữa các chỉ số }\end{array}$ & Nhóm 1 & Nhóm 2 \\
\hline $\begin{array}{c}\text { Trưc nhãn cầu và } \\
\text { khúc xa giác mạc }\end{array}$ & $\mathrm{r}=-0.235$ & $\mathrm{r}=-0,025$ \\
$\mathrm{p}=0,054$ & $\mathrm{p}=0,809$ \\
\hline
\end{tabular}

Khi tìm hiểu mối liên quan giữa chiều dài trục nhãn câu và khúc xạ giác mạc theo từng mức độ cận thị chúng tôi nhận thấy: ở các nhóm mức độ cận thị cao không có mối tương quan tuyến tính giữa chiều dài trục nhãn cầu và khúc xạ giác mạc với $p>0,05$. Khác với kết quả nghiền cứu của Nguyễn Thị Thanh Dung năm $2017^{6}$ thấy rằng hai chỉ số chiều dài trục nhãn cầu và khúc xạ giác mạc có mối tương quan nghịch biến (với $\mathrm{r}=-0,605$ và $\mathrm{p}<0.001$ ). Xét riêng trong từng nhóm cận thị, cũng tìm thấy mối tương quan nghịch biến khá chặt chẽ giữa chiều dài trục nhãn câuu và khúc xạ giác mạc. Điều đó có thể do số lượng bệnh nhân của chúng tôi chưa đủ lớn để thấy được mối liên quan này.

\section{KẾT LUẬN}

Qua nghiên cứu mô tả cắt ngang trên 168 mắt của 88 bệnh nhân từ 12 tuổi trở lên được chẩn đoán là cận thị cao (trên -6.00D) cho thấy:

- Khúc xạ giác mạc trung bình là $43.16 \pm$ 1.369D. Không có sự khác biệt khúc xạ giác mạc giữa các nhóm cận thị cao. Chiều dài trục nhã̉n cầu trung bình là $27,33 \pm 1,49 \mathrm{~mm}$. Chiều dài trục nhãn cầu ở nhóm 2 dài hơn so với nhóm 1 $(p<0,001)$.

- Khúc xạ giác mạc trung bình và mức độ cận thị trên mắt cận thị cao có tương quan tuyến tính $(r=-0,209$ và $p=0,007)$. Chiều dài trục nhãn cầu trung bình và mức độ cận trên mắt cận thị cao có mối tương quan tuyến tính chặt chẽ ( $r=-$ $0,762$ và $p<0,0001)$. Khúc xạ giác mạc và chiều dài trục nhãn câu không có mối liên quan có ý nghĩa thống kê.

\section{TÀI LIỆ THAM KHẢO}

1. Saw S-M, Matsumura S, Hoang QV. Prevention and Management of Myopia and Myopic Pathology. Invest Ophthalmol Vis Sci. 2019;60(2):488-499.

2. Holden BA, Fricke TR, Wilson DA, et al. Global Prevalence of Myopia and High Myopia and Temporal Trends from 2000 through 2050. Ophthalmology. 2016;123(5):1036-1042.

3. Baradaran-Rafii A., Fekri S., Rezaie M. et al. Accuracy of Different Topographic Instruments in Calculating Corneal Power after Myopic Photorefractive Keratectomy. J Ophthalmic Vis Res. 2017;12(3):254-259.

4. Kadhim Y.J., Farhood Q.K. Central corneal thickness of Iraqi population in relation to age, gender, refractive errors, and corneal curvature: a hospital-based cross-sectional study. Clin Ophthalmol Auckl NZ. 2016;10:2369-2376.

5. Olsen T., Arnarsson A., Sasaki H. et al. On the ocular refractive components: the Reykjavik Eye Study. Acta Ophthalmol Scand. 2007;85(361-366).

6. Nguyễn thi Thanh Dung. Đánh giá các chỉ số: trục nhãn câuu, độ dày giác mạc, khúc xạ giác mạc và độ sâu tiền phòng trên mắt cận thị ở lứa tuổi thanh niên. Luân văn thạc sỹ y học, Đại học Y Hà Nội, Hà Nội. 2017.

7. Chen M.-J., Liu Y.-T., Tsai C.-C., et al. Relationship between central corneal thickness, refractive error, corneal curvature, anterior chamber depth and axial length. J Chin Med Assoc. 2009;72(3):133-137. 